\title{
IS IT POSSIBLE TO USE LOW-COST INFRARED CAMERAS (THERMAL RESOLUTION OF 80X60 PIXELS) IN MEDICAL APPLICATIONS?
}

\section{Eduardo Borba Neves' ${ }^{1}$, Marcos Leal Brioschi ${ }^{2}$}

${ }^{1}$ Brazilian Army Research Institute of Physical Fitness

2 São Paulo University

The science has observed a great evolution of the use of the thermal images in the medicine and related areas in the last 20 years. However, the cost of equipment has limited its use. Recently some lowcost equipment (with thermal resolution of $80 \times 60$ pixels) reached the market.

Several authors ${ }^{1-3}$ have recommended the use of equipment with a minimum resolution of $320 \times 240$ pixels. However, the use of low-cost thermal cameras can be targeted to specific applications, or subjected to digital image processing methods that enhance their use.

The main limitation of low-cost thermal cameras is their thermal resolution (80x60 pixels). Figure 1 shows two images, a whole-body thermal image (320x240 pixels) and a fraction of that image, only the face, with (80x60 pixels). This means that making a face image of a subject with a low cost thermal camera provides the same thermal information that would be obtained from a whole-body thermal image (with a thermal resolution of 320x240 pixels) in which we had as objective any region of interest on the face.
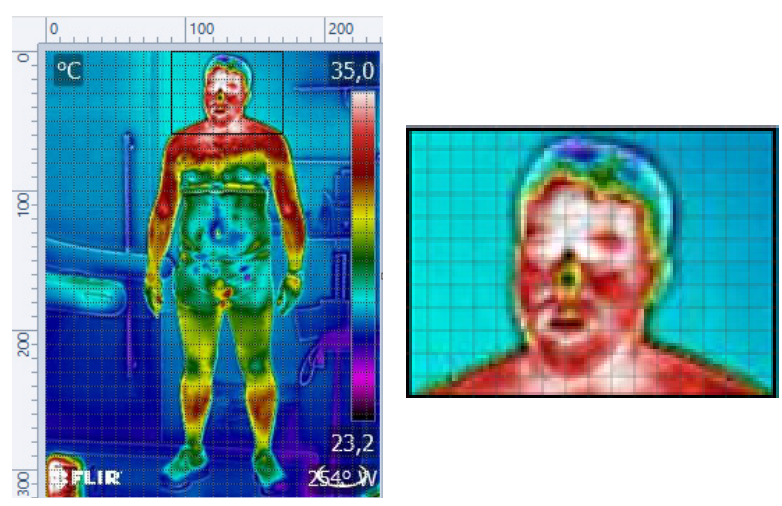

(a) Whole-body Thermal Image

(b) Fraction of whole-body Thermal Image ( $80 \times 60$ pixels)

FIGURE 1 (a) Whole-body Thermal Image (320x240 pixels) and (b) a fraction of image (a) with $80 \times 60$ pixels 
Another way of using cost-effective thermal cameras is by applying digital image processing methods. Authors ${ }^{4}$ reported that the use of total variation constrained deconvolution method can enhanced thermal image from the low-resolution infrared (IR) cameras making it comparable to that from a high-resolution IR camera. They concluded that total variation constrained deconvolution method provides an effective improvement the thermal image quality from a low-cost IR camera to evaluate temperature of an object of 1-mm size. Some manufacturers are already incorporating new technologies into low-cost thermal cameras, such as MSX (Multi Spectral Dynamic Technology) which provide physical details to the raw thermal image ${ }^{5}$, and therefore, resulting in a better vision and allowing good anatomical and thermal interpretations (Figure 2).

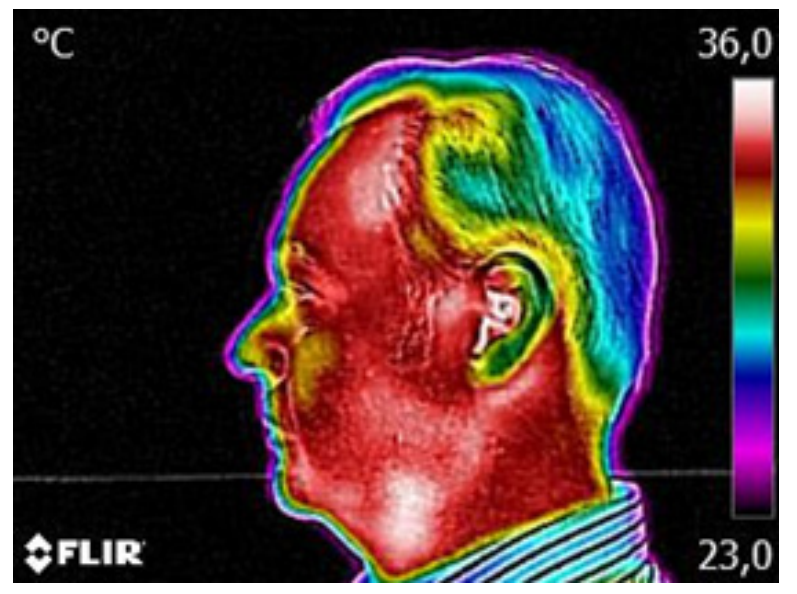

FIGURE 2 Thermal image from a FLIR C2 in MSX mode.
In this sense, it can be concluded that low-cost thermal cameras can be used in medical applications when the region of interest (ROI) is small or the user will apply any kind of digital image processing methods, which improve the quality of the thermal images.

\section{REFERÊNCIAS}

1. Neves EB, Reis VM. Fundamentos da termografia para o acompanhamento do treinamento desportivo. Rev Uniandrade. 2014; 15(2):79-86.

2. Bandeira F, Neves EB, Moura MAMd, Nohama P. A termografia no apoio ao diagnóstico de lesão muscular no esporte. Rev Bras Med Esporte. 2014; 20(1):59-64.

3. Brioschi ML, Teixeira MJ, Yeng LT, Silva FMRM. Manual de Termografia Médica. 1 ed. São Paulo: Andreoli; 2012.

4. Lai F, Kandukuri J, Yuan B, Zhang Z, Jin M. Thermal image enhancement through the deconvolution methods for low-cost infrared cameras. Quantitative InfraRed Thermography Journal. 2018:1-17.

5. Fraiwan L, AlKhodari M, Ninan J, Mustafa B, Saleh A, Ghazal M. Diabetic foot ulcer mobile detection system using smart phone thermal camera: a feasibility study. Biomedical engineering online. 2017; 16(1):117. 